\title{
Noticias de la AEP
}

\section{Cómo responden las familias a la infección por VIH en uno de sus miembros}

\author{
C. L. Cazzullo
}

Associazione Richerche Schizofrenia, Via Tamagno 5, 20123, Milán, Italia

\section{INTRODUCCIÓN}

La familia está expuesta constantemente a la angustia y el sufrimiento de sus miembros debido a su proximidad física y psíquica. Cuando los miembros de una familia caen enfermos, causan una turbulencia mucho más grave y profunda dentro del contexto familiar, que amplifica el sufrimiento, modificando los mecanismos y la capacidad de defensa.

Las enfermedades graves y sus implicaciones sociales afectan profundamente, en compañía de aquellos a los que aqueja de manera directa, a los familiares del paciente y crean un velo de dolor, ansiedad y tristeza, que pueden llevar a la desesperación. Entre estas enfermedades, la infección por el virus de la inmunodeficiencia humana (VIH) ha asumido recientemente un papel particular (Maj, 1996).

Cuando pensamos en el problema de la enfermedad por VIH y el paciente seropositivo, no debemos olvidar al tercer personaje que participa siempre tanto en primer lugar como en la implicación a largo plazo en los acontecimientos relacionados con la enfermedad: la familia del paciente. Ciertas consideraciones generales merecen ser introducidas, pues afectan a la dinámica familiar. En el contexto de la familia, existen fenómenos dinámicos relacionados con el sufrimiento del miembro enfermo de la familia que modifican las reacciones de sus otros miembros y precipitan la aparición de sentimientos de angustia o exacerban perturbaciones preexistentes. A menudo, el médico es la primera persona que encuentra estas situaciones, y el manejo profesional y ético que se haga de ellas es con frecuencia crucial.

Las tensiones dentro de las familias, el llamado "clima emocional", se pueden reconocer por un análisis de la emoción expresada (EE). Se ha estudiado mucho la EE en la investigación de la esquizofrenia, donde se considera que es un factor de riesgo psico- social relacionado. Un nivel elevado de EE, caracterizado habitualmente por la asociación de sobreimplicación emocional, crítica u hostilidad, afecta negativamente a la incidencia de la recaída en la esquizofrenia, que puede alcanzar el $90 \%$, especialmente en ausencia de factores protectores como la medicación neuroléptica. Por otra parte, en presencia de calidez afectiva y empatía, la tasa de recaídas se reduce a la mitad (Bertrando et al, 1992).

En los casos de depresión, los niveles altos de EE, es decir, las actitudes hostiles o la sobreimplicación emocional de otros miembros de la familia, son también causa de que la incidencia media de la recaída sea más alta en comparación con los controles con EE baja. Se ha encontrado que las esposas de los pacientes deprimidos eran más críticas que sus maridos tanto hacia ellos como hacia sus hijas. El intento de suicidio, que es prevalente en los sujetos femeninos hasta los 21-22 años de edad, está correlacionado en más del $80 \%$ de los casos con un nivel alto de EE (Beckerman, 1995).

Los resultados encontrados en los casos de adicción a drogas mostraron que, en los perfiles familiares, había con frecuencia un nivel alto de EE que era comparable al encontrado en los perfiles correspondientes de los esquizofrénicos (Cazzullo et al, 1990). Por tanto, la investigación del clima emocional de la familia ha mostrado su pertinencia en psiquiatría y psicología médica. Su aplicación a la infección por VIH puede ser igual de importante.

\section{REACCIONES EMOCIONALES DEL PACIENTE CON VIH}

En los últimos años se ha indicado, cuando se analizaba el problema desde el punto de vista del paciente, el enorme cambio que se produce en su existencia al descubrir, a veces de modo bastante brutal, que está infectado. Sin embargo, más recientemente la brutalidad de este cambio ha disminuido mucho, o, al menos, se ha hecho menos pronunciada. El notable cambio pronóstico con respecto a la infección por VIH debido al progreso de la investigación científica (por ejemplo, la eficacia de la terapia antirretroviral, el desarrollo de una nueva generación de fármacos antirretrovirales, los inhibidores 
de la proteasa) ha desplazado el acontecimiento más critico a lo largo del eje temporal, desde el descubrimiento de la infección hasta el comienzo del sida (Carpenter et al, 1996; Mellors et al, 1995).

El estrés es más agudo en estas fases de inmunodepresión graves, cuando el paciente se da cuenta de que está en la zona de peligro y no puede escapar (Atkinson et al, 1988; Cazzullo et al, 1989). La amenaza a la propia integridad personal puede ser tal que exista un peligro de que la propia individualidad pierda apoyo. Los pacientes pueden experimentar un ataque a su condición misma de persona, tanto en el sentido físico como en el psicológico, debido al modo en que la sociedad culpabiliza a los pacientes de sida. Hay varias fases en el desarrollo de la ansiedad; el paciente no pasa necesariamente por todas ellas en rápida secuencia, pero son suficientes para modificar en profundidad los aspectos existenciales de la vida del paciente. La fase de estrés tiene dos características, una formal y otra sustancial. La primera se refiere a los aspectos más inmediatos de la conducta, donde predomina un sentimiento de malestar junto con un desconcierto o incluso incredulidad trágica. En algunos casos se ve un aumento en la comunicación interpersonal, que puede ser demasiado abierto e incluso imprudente. La noticia se puede revelar en confianza al miembro más próximo de la familia, en la mayoría de los casos la madre o el compañero sentimental. El paciente se niega con frecuencia a hablar sobre su difícil situación y sólo su conducta refleja los efectos del conocimiento de la infección.

La otra característica es más sustancial y sus efectos se ven en una fecha posterior. Es la consciencia de la pérdida, la convicción de que la posesión más preciosa de la persona, la salud, está en peligro. La depresión es la expresión más simétrica de esta característica, y es más o menos profunda según la consciencia de la pérdida (es decir, la certidumbre) domine sobre el sentimiento de pérdida (que incluye un elemento de duda).

\section{EL PACIENTE CON VIH Y EL MEDIO FAMILIAR}

En el título de este artículo la palabra "familias" aparece en plural, en comparación con el singular; por tanto, se subraya que muchos tipos diferentes de disposiciones sociales caben bajo este encabezamiento.
Hay familias de origen, familias en que las personas viven juntas sin estar casadas, uniones entre dos individuos solteros (por ejemplo, homosexuales), y uniones que implican grupos o comunidades. El término "familia", aunque no es técnicamente preciso en estos casos, se utiliza a menudo en el habla cotidiana, transmitiendo (quizá inconscientemente) la idea de un "puerto seguro", de un nido protector.

Las diferentes situaciones implican un efecto "personalizado" de la conducta del paciente hacia la familia y de la conducta de ésta hacia el miembro infectado. Es importante aquí tomar en consideración las características de la familia antes del juicio médico.

Las familias en las que uno de los miembros tiene infección por VIH están con claridad entre aquellas en las que más problemas suscita el enfrentamiento con una condición médica. Se pueden producir dos situaciones: los aspectos negativos de la conducta se acentúan (especialmente en los casos de adicción a drogas) hasta el punto de que el paciente puede ser rechazado de la unidad familiar, o ésta puede ofrecer compasión y ayuda. Por tanto, la condición psicológica de sus miembros antes de cualquier forma de intervención desempeña un papel importante.

En un porcentaje bastante significativo de casos (aproximadamente 17-18\% en uno de nuestros estudios anteriores [Cazzullo et al, 1989]), encontramos que había habido contacto previo entre los servicios psiquiátricos de los pacientes y sus familias. Además, el número de intentos de suicidio y de suicidios consumados está por encima de la media de la población cuando se revisa la historia previa de los sujetos positivos. Existe un notable aumento en este porcentaje (18-24\%) en los sujetos que han contraído la infección por VIH (Cazzullo et al, 1989; Cazzullo et al, 1990; Catalan et al, 1995).

Como se puede ver en las publicaciones referentes a este asunto (Grummon et $\mathrm{al}, 1994)$, existe un acuerdo general de que los factores ambientales son muy importantes en la conducta suicida, y en los intentos de suicidio en jóvenes estos factores predominan de la manera más absoluta. La familia desempeña un papel sumamente negativo, en especial porque está ausente en el momento en que se emite el grito de ayuda, tanto cuando éste se comunica abiertamente, lo que es poco frecuente, como cuando se transmite indirectamente (10). Existe una situación análoga con los adictos a las drogas, 
cuyas familias, como hemos visto, muestran un elevado nivel de EE que facilita la recaída en el $80 \%$ de los casos (Cazzullo et al, 1990).

La condición básica de la familia es, por tanto, esencial (tanto en términos de aceptación como de rechazo) para una ruptura o en el mantenimiento de la comunicación, incluso si es el más precario de los diálogos.

\section{LA REVELACIÓN DE LA INFECCIÓN POR VIH A LA FAMILIA}

En los casos de infección por VIH, entra en juego otro factor en la relación entre el paciente y la familia. Es el mmomento en que ésta se entera de la infección en relación con la cantidad real de tiempo que el sujeto ha sabido que era seropositivo. Este fenómeno se investigó, aunque no sistemáticamente, observando la modalidad de admisión del paciente en un servicio ambulatorio.

Durante un periodo de 2 años en la Clínica de Dermatología y Enfermedades de Transmisión Sexual dirigida por la Universidad de Milán, se encontró que en $95 \%$ de los casos los pacientes acudían solos al servicio de pacientes externos. La familia rara vez está presente al principio, no debido a una falta suya, sino porque el paciente los mantiene en completa ignorancia. Si éste vive todavía con ellos (esto se aplica tanto a los homosexuales como a los adictos a drogas) normalmente está muy preocupado por la idea de ser expulsado de la unidad familiar. Esta preocupación es incluso más fuerte cuando el sujeto es joven y disfruta todavía del sentido de protección, aunque incompleto, que ofrece el núcleo familiar.

En la segunda, tercera o cuarta entrevista, el paciente puede aparecer con un miembro de la familia o con su compañero sentimental. Las mujeres parecen ser más "fieles" y estar más dispuestas, al menos inicialmente, a proteger al paciente. Los homosexuales es más frecuente que vengan acompañados de sus compañeros sentimentales, y casi nunca de miembros de su familia.

La familia ha asumido a menudo una actitud particular hacia los miembros de la población general en riesgo de infección por VIH. Los adictos a drogas ya se han ido de casa, de manera que la expulsión activa se combina con un distanciamiento espontáneo por el propio paciente.
Sin embargo, deberíamos consignar la actitud protectora de las familias que no han expulsado al adicto a drogas de su núcleo, lo mismo que la de aquellas que han vuelto a admitir al miembro que ya ha dejado de utilizarlas. Por ejemplo, en los casos de antiguos adictos a drogas que se han abstenido de usarlas durante 10 años y se encuentran entonces con que son seropositivos, la familia ha reconocido sus intentos de rehabilitación y ha resultado ser protectora, compasiva y de gran ayuda práctica.

Son las familias de los homosexuales las que muy a menudo desconocen que un miembro es seropositivo y siguen sin saberlo durante largo tiempo, hasta que la enfermedad se hace manifiesta. La actitud protectora puede asumir diversas formas y canalizarse o bien hacia el paciente o bien hacia el grupo entero. A veces, la familia pide una nueva prueba serológica para el sujeto infectado, o el paciente insiste en que toda ella la realice, compartiendo así un sentimiento de responsabilidad con sus familiares. Los compañeros sentimentales, sean homosexuales o heterosexuales, solicitan una prueba de VIH motivados frecuentemente por un sentimiento de culpa que puede adoptar proporciones dramáticas.

El efecto de la intranquilidad subyacente o la enfermedad previa es más grave en los casos de unión heterosexual pasajera que en las relaciones homosexuales, o incluso en los núcleos familiares establecidos que no han perdido, sin embargo, su sentido de cohesión.

Existe una heterogeneidad enorme entre los pacientes positivos al VIH. Sin embargo, después de recibir la noticia de la infección todos expresan el deseo imperioso, que no siempre se puede hacer realidad, de compartir este drama personal con otros. En un grupo de 30 pacientes examinado en la Sala de Enfermedades Infecciosas del Hospital de Cremona, todos a excepción de dos expresaron la necesidad de sentir la calidez de la aceptación, si no de sus familias, sí de los compañeros sentimentales de otras personas seropositivas en la misma situación. Algunas personas querían formar un grupo de seropositivos y encontrar un espacio donde pudieran reinventarse a sí mismos en la angustiada dimensión de este acontecimiento inalterable. Este grupo tiene la sensación neta de un límite casi definido para su propia existencia, pero deriva energía de una especie de solidaridad social que le anima a 
solicitar sesiones de información para las familias con miembros seropositivos, de manera que puedan darse cuenta de lo que significa exactamente vivir en estas situaciones.

De los 30 pacientes mencionados, cuatro fueron aceptados por la familia en un espíritu de solidaridad con fuerte apoyo psicológico. Otros 15 pacientes fueron aceptados por la familia, pero con una serie de recriminaciones y con poca ayuda psicológica. Uno de estos pacientes, un homosexual de 30 años, explicó: "Cada vez que nos sentamos a comer mi madre me dice que todo es culpa mía". Después de descubrir que estaban infectados, cuatro pacientes tuvieron que separarse o dejar a su familia, tres viven en una comunidad y cuatro viven solos.

La familia es menos probable que expulse al paciente cuando la infección se ha verificado, y se hace más protectora, aunque la dialéctica en su interior puede hacerse tan insistente que distancie al paciente, que trata de escapar del abrumador sentimiento de culpa sentido fuera, combinado con la culpa sentida dentro, que no cesa nunca, excepto en la fase de deterioro cognitivo grave (es decir, el complejo de demencia por el sida).

\section{COMUNICACIÓN INTRAFAMILIAR Y ACEPTACIÓN DE LA ENFERMEDAD}

Tanto el paciente de sida como la familia se encuentran en realidad en un estado de incapacidad impuesta para comunicarse, lo mismo para preservar una cierta sociabilidad residual que para no degradar más su imagen de su propia condición de persona. La soledad es el resultado inmediato y le sigue de cerca el aislamiento, y en algunos casos el abandono.

La pérdida de reconocimiento, que es el respeto por la propia individualidad, induce un comienzo más o menos rápido y profundo de una perturbación grave del estado de ánimo que puede llevar incluso al suicidio. El paciente seropositivo teme debatir su condición con otros por miedo a ser relegado al ostracismo. Esto difiere de los pacientes de cáncer, que, con la ayuda de su familia, pueden librar valientemente su batalla.

El sufrimiento de los pacientes irreflexivos y transgresores puede aumentar por los conflictos frecuentes entre los miembros del núcleo familiar, con el riesgo de dividir y, así, disminuir la posibilidad de ayuda recíproca. Kubler-Ross (1968), uno de los principales expertos en el fenómeno de la respuesta psicológica a la enfermedad, observó que la adaptación, tanto por parte de la familia como por parte del paciente, a una muerte inminente (real o imaginaria) afecta a la personalidad de los implicados y a las relaciones dentro de la familia.

Sin embargo, si la conducta del paciente está influida profunda y constantemente -en un sentido positivo- por la familia, encontramos que el paciente mejora desde un punto de vista clínico y hay más energía individual y colectiva que se ha perdido durante algún tiempo o quizá sólo ha cristalizado. Sigue una evolución inesperada y un aumento de los recursos útiles que ayudan a tolerar los efectos negativos de la enfermedad que ya no se puede superar.

Cuando la familia tiene apoyo y consenso social puede adoptar de nuevo un papel importante y positivo. Ayudar a comprender mejor un problema y ofrecer solidaridad son prioridades al garantizar soluciones rápidas válidas para los que sufren. La comunicación y las relaciones interpersonales se deberían recordar como herramientas de tratamiento muy útiles.

\section{AGRADECIMIENTOS}

Quiero dar las gracias al Prof. Alessi, a los doctores Cusini, Bessie, Pedrzzoli y Magotti y al Prof. Casagrande por su valiosa colaboración.

\section{BIBLIOGRAFÍA}

Atkinson JH, Gant I, Kennedy CJ, Richman DD, Spector SA, McCutchan JA. Prevalence of psychiatric disorders among men infected with HIV. A controlled study. Arch Geo Psychiatry 1988; 45: 859-64.

Beckerman NL. Suicide in relation to AIDS, Death Stud 1995; 19: 223-34.

Bertrando P, Beltz J, Bressi C, Clerici M, Fama T, Invarnizzi G, Cazzullo CL. Expressed emotion and schizophrenia in Italy. A study of an Italian population. $\mathrm{Br}$ J Psychiatry 1992; 161: $223-9$.

Carpenter CC, Fisehl MA, Hammer SM, Hirsch MS, Jacobsen FM, Katzenstein DA. Antiretroviral therapy for HIV infection in 1996. JAMA 1996; 276: 146-154.

Catalan J, Seijas D, Lief T, Pergami A, Burgess A. Suicidal behaviour in HIV infection: a case-control stud of deliberate self-harm in people with HIV infection. Arch Suicide Research 1995; 1: 85-96. 


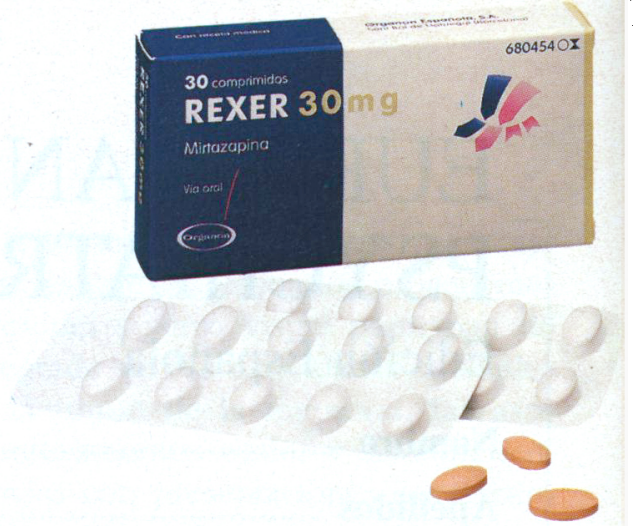

Cazzullo CL, Gala C, Martini S, Pergarni A, Rossini M, Russo R. Evaluation psychiatrique des sujets atteints d'infection HIV. Psychol Medical 1992; 24: 1521-4.

Cazzullo CL, Gala C, Riccio M, eds. AIDS: insidia biologica e disagio psicosociale. Torino: UTET, 1990.

Grummon K, Dwyer Rigby E, Orr D, Procidano M, Reznikoff adjustment of IVDU patients with AIDS. J Clin Psychol 1994; 50: 488-502.

Maj M. Depressive syndromes and symptoms in subjects with Human Immunodeficiency Virus infection. $\mathrm{Br} J$ Psychiatry 1996; 168 (suppl 39): 117-22.

Mellors JW, Kinsley L, Rinldo CRJ et al. Quantitation of HIV-1 RNA in plasma predicts outcome after seroconversion. Intern Med 1995; 122: 573-9.

Kubler-Ross E. On Death and Dying. New York: Macmillan, 1968.
REXER. Comprimidos de $30 \mathrm{mg}$ de mintazapina. Indicaciones: Episodio de depresión mayor. Posología y forma de administración: Vía oral, tragar con o sin líquido, sin masticar. Adultos: Inicio con $15 \mathrm{mg} /$ dáa, aumentando hasta obtener una respuesta óptima. La dosis eficaz suele estar entre 15 y $45 \mathrm{mg} /$ día. Ancianos: La dosis recomendada es la misma que para los adultos, pero el aumento de dosis debe realizarse bajo supervisión. Niños: No se ha determinado la eficacia y seguridad de Rexer en niños. Tener en cuenta que el aclaramiento de mirtazapina puede disminuir en pacientes con insuficiencia hepática o renal. Mirtazapina tiene una semivida de $20-40$ horas, por lo que puede administrarse como dosis única, preferiblemente antes de acostarse También puede administrarse en dos subdosis divididas a partes iguales durante la jornada (mañana y noche). Es recomendable continuar el tratamiento durante 4-6 meses más desde la ausencia de síntomas y puede finalizarse gradualmente. El tratamiento con dosis adecuada deberá proporcionar respuesta positiva en 2-4 semanas. Si la respuesta es insuficiente, la dosis puede aumentarse hasta la dosis máxima, pero si no se produce respuesta en otras 2.4 semanas, deberá abandonarse el tratamiento. Contraindicaciones: Hipersensibilidad a la mirtazapina. Advertencias y precauciones Contraindicaciones: Hipersensibilidad a la mirtazapina. Advertencias y precauciones:
Durante el tratamiento con muchos antidepresivos se ha descrito depresión de la médula ósea, que suele evidenciarse como granulocitopenia o agranulocitosis, casi siempre aparece después dé $\mathbf{4} \cdot \mathbf{6}$ semanas, siendo en general reversible una vez suspendido el tratamiento. También se ha informado de agranulocitosis reversible como acontecimiento adverso raro en estudios clínicos con Rexer. Deberá vigilarse la aparición de fiebre, dolor de garganta, estomatitis u otros signos de intección; si se presentan tales síntomas deberá suspenderse el tratamiento y realizarse un hemograma. En los siguientes casos es necesario establecer cuidadosamente la pauta posológica y realizar un seguimiento regular: epilepsia y síndrome afectivo orgánico (aunque raramente se producen ataques en pacientes tratados con Rexer), insuficiencia hepática o renal, enfermedades cardíacas como alteraciones de la conducción, angina de pecho e infarto de miocardio reciente (situaciones en las que deberán tomarse las precauciones habituales y administrar con precaución los medicamentos concomitantes) e hipotensión. Al igual que con otros antidepresivos deben tomarse precauciones en pacientes que se encuentren en las siguientes situaciones altenciones de b micción por hipestrofia prostática y glaucoma de ángulo agudo con presión intraocular elevada (aunque en ambos casos no es de esperar que se produzcan problemas debido a que (aunque en ambos casos no es de esperar que se produzcan problemas debido a que el tratamiento si se presenta ictericia. Además, al igual que con otros antidepresivos, debe tenerse en cuenta que puede darse un empeoramiento de los síntomas psicóticos cuando se administran antidepresivos a pacientes con esquizofrenia u otras alteraciones psicóticas; pueden intensificarse los pensamientos paranoides; puede revertirse a la fase maniaca si se trata la fase depresiva de una psicosis maniaco-depresiva; respecto a la posibilidad de suicidio, en casos particulares, sobre todo al inicio del tratamiento debe proporcionarse al paciente un número limitado de comprimidos de Rexer. debe proporcionarse al paciente un número limitado de comprimidos de Rexer.
Aunque los antidepresivos no producen adicción, la suspensión brusca de tratamiento Aunque los antidepresivos no producen adicción, la suspensión brusca de tratamiento malestar. A veces los pacientes ancianos son más sensibles a los efectos de los antidepresivos, sobre todo en cuanto a los efectos adversos, durante la investigación clínica con Rexer no se han recogido diferencias entre los grupos de edad en aparición de efectos adversos, sin embargo la experiencia hasta el momento es depriva Mirtazapina puede potencia la acción depresiva del alcohol sobre el sistema nervios central, por tanto los pacientes deben evitar el alcohol durante el tratamiento con Rexer. Rexer no debe administrarse simultáneamente con inhibidores de la MAO o en las dos semanas posteriores a la finalización del tratamiento con estos agentes. Mirtazapina puede potenciar los efectos sedantes de las benzodiacepinas. Embarazo y lactancia: Aunque los estudios en animales no han mostrado ningún efecto teratogénico con trascendencia toxicológica, no se ha establecido la seguridad de Rexer en el embarazo humano. Rexer se utilizará en el embarazo sólo si la necesida es clara. Las mujeres en edad de concebir deberán utilizar un método anticonceptivo adecuado si se tratan con Rexer. Aunque los experimentos en animales muestran que mirtazapina se excreta en cantidades muy pequeñas por la leche, el uso de Rexer en mujeres lactantes no es aconsejable por no existir datos sobre la excreción por la leche humana. Efectos sobre la capacidad para conducir vehículos y utilizar maquinaria: Rexer puede disminuir la concentración y la alerta. Los pacientes en tratamiento con antidepresivos deben evitar realizar actividades potencialmente peligrosas que requieran un estado de alerta y concentración, como conducir un vehículo a motor o manejar maquinaria. Reacciones adversas: Las reacciones vehiculo a motor o manejar maquinaria. Reacciones adversas: Las reacciones
adversas más frecuentes durante el tratamiento con Rexer son; aumento de apetito y aumersas más frecuentes durante el tratamiento con Rexer son: aumento de apetito y aumento de peso; somnolencia/sedación, generalmente durante las primeras semanas y además puede comprometer la eficacia antidepresiva). En casos raros puede presentarse hipotensión (ortostática), manía, convulsiones (ataques), temblores, mioclonía, edema, depresión aguda de la médula ósea (eosinofilia, granulocitopenia agranulocitosis, ancmia aplásica y trombocitopenia) (ver" "Advertencias y precauciones") aumento en las transaminasas séricas y/o exantema. Sobredosificación: No se ha establecido la seguridad clínica de Rexer por intoxicación. Los estudios de toxicidad no mostraron efectos cardiotóxicos relevantes en intoxicación con Rexer, y en los ensayos clínicos tampoco se observaron efectos de importancia clínica por sobredosificación, aparte de sedación excesiva. La sobredosificación deberá tratarse mediante lavado gástrico más una terapia sintomática apropiada y apoyo de las funciones vitales. Incompatibilidades: Ninguna. Presentaciones: Los comprimidos se presentan en blisters de seguridad a prueba de niños, con película opaca de cloruro de polivinilo de color blanco y lámina de aluminio, en envases de 30 comprimidos rojo pardo de $30 \mathrm{mg}$ de mirtazapina. PVPIVA(NM): 8395 , Pts. Instrucciones de rojo pardo de $30 \mathrm{mg}$ de mirtazapina. PVPVA(NM): 8395 ,- Pts. Instrucciones de uso/manipulación: Ninguna en especial. Condiciones de prescripción y
dispensación. Prestación farmacéutica del S.N.S. Con receta médica. Incluido en la prestación. Aportación reducida. RU M 1060.041.101/2.PU Organon Española S.A. C/ Castelló nº, 08830 Sant Boi de Llobregat (Barcelona). 

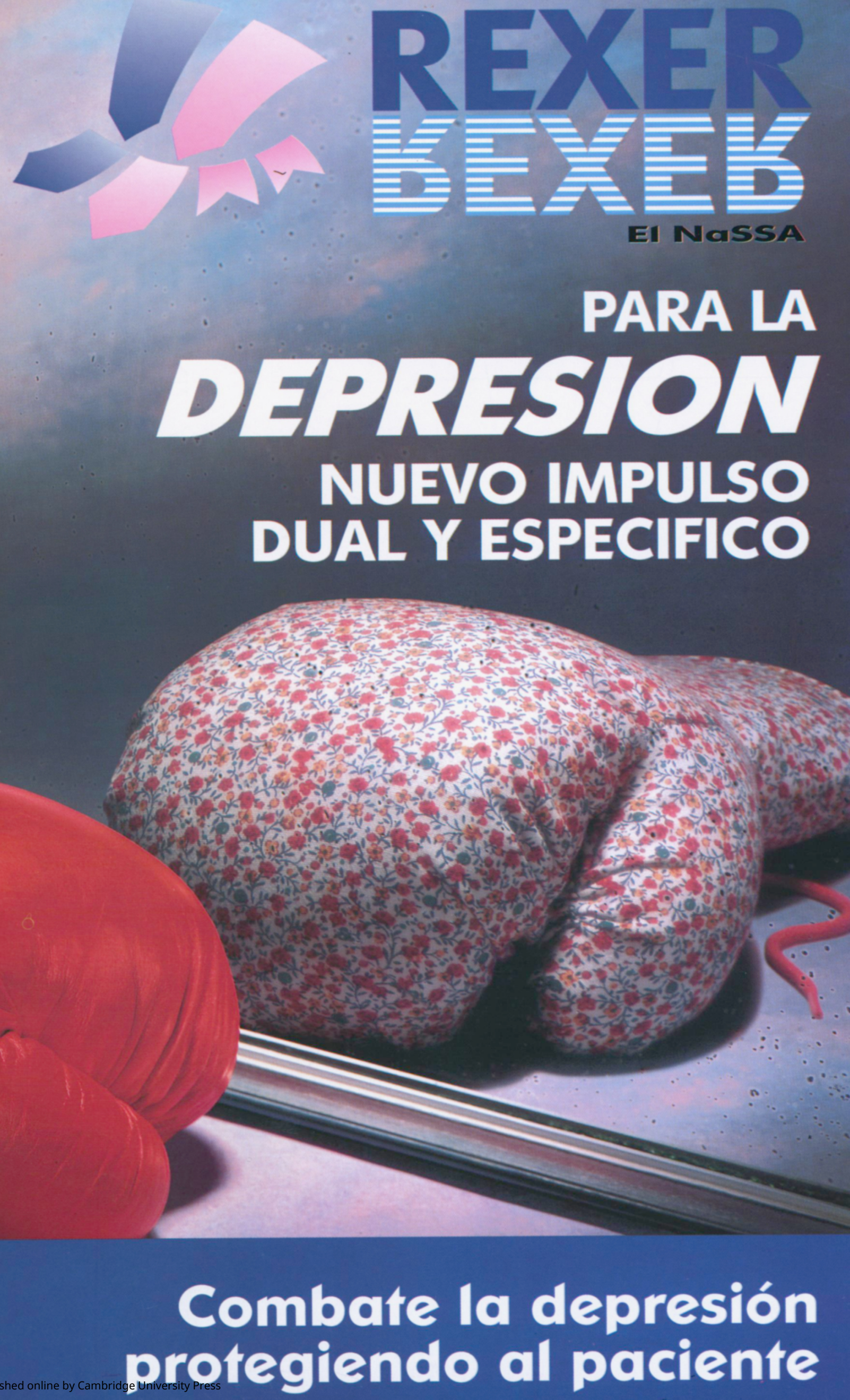